\title{
Topographical and chemical effects of electrochemically assisted deposited hydroxyapatite coatings on
} osteoblast-like cells.

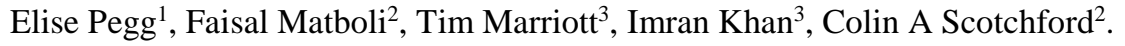 \\ ${ }^{1}$ Nuffield Department of Orthopaedics, Rheumatology and Musculoskeletal Sciences, University of Oxford, OX3 \\ $7 \mathrm{LD}$. \\ ${ }^{2}$ Bioengineering Research Group, Division of Materials, Mechanics and Structures, Faculty of Engineering, \\ University of Nottingham, University Park, Nottingham, NG7 2RD, UK. \\ ${ }^{3}$ Biomet UK Healthcare Ltd. Dorcan Industrial Estate, Swindon, SN3 5HY, UK
}

\begin{abstract}
A recently commercialised hydroxyapatite electrochemically-assisted chemical deposition technique (BoneMaster) has been shown to induce increased bone apposition; whether this response is caused by the surface topography or chemistry is unknown. An in-vitro examination using human osteoblast-like cells was performed on a series of BoneMaster coated surfaces. The chemistry was separated from the topography using a thin gold coating; Thermanox slides were used as a control. BoneMaster surfaces showed significantly greater alkaline phosphatase activity and osteocalcin production compared with controls; however, no difference was found between the goldcoated and uncoated BoneMaster samples, indicating topography is the main contributing factor.
\end{abstract}

KEY WORDS: fixation, hydroxyapatite, bone, topography, chemistry, surface

\section{INTRODUCTION}

The first hydroxyapatite coating was applied to a primary hip by Furlong and was implanted in 1985 [1]. The purpose of the coating was to mimic the chemistry of bone and thus increase bony fixation at the implant interface; the success of these coatings has resulted in them being widely used throughout the orthopaedic industry. However, aseptic loosening is still a major cause of failure of orthopaedic components [2] which needs to be addressed.

One of the possible issues with any coating is delamination, and there have been reports of hydroxyapatite coatings separating from the underlying metal [3, 4]. Hydroxyapatite coatings are normally plasma sprayed and have a thickness between $70 \mu \mathrm{m}$ and $170 \mu \mathrm{m}$ [3]; excessive coating thickness can cause residual stresses to build up within the coating and this can result in delamination [5, 6]. For this reason, plasma-sprayed hydroxyapatite coatings are regularly tested by orthopaedic manufacturers in accordance with ASTM C-633 [7] to minimise the risk of delamination.

Plasma sprayed coatings have a chemical composition which is similar to that of bone, although not exactly the same. The high temperatures used in the coating process can cause extra phases of calcium phosphate to form; these include amorphous calcium phosphate, $\alpha$ - and $\beta$ - tricalcium phosphate, tetracalcium phosphate and calcium oxide 
[8]. These other phases are not present in the mineral phase of natural bone; natural bone consists of hydroxyapatite substituted with small amounts of carbonates, silicon and magnesium.

A novel biomimetic hydroxyapatite (HA) coating, commercially called BoneMaster, has been developed which uses a deposition technique based on an electrochemically assisted precipitation process [9]. The aim of the coating is to closely mimic both the chemistry, and the topography, of natural bone. To create the coating, a current is passed through the implant while it is in a super-saturated solution of ionic calcium phosphate; the current causes a $\mathrm{pH}$ increase at the surface of the implant which induces the calcium and phosphate ions to precipitate out onto the surface of the component. The initial phase produced is amorphous calcium phosphate, but with time this crystallizes out into hydroxyapatite needles; mimicking the in vivo mineralization process. The coating process is carried out under near-physiological conditions; $37^{\circ} \mathrm{C}$ and $\mathrm{pH}$ 6.4. The resultant coating is only $5 \mu \mathrm{m}$ thick, therefore reducing the potential for large residual stresses within the coating and the likelihood of delamination.

The biological performance of the electrochemically deposited hydroxyapatite coatings has been investigated previously through in vivo studies by Schliephake et al. [10]; the study found increased bone-implant contact during the early ingrowth period onto the BoneMaster coated samples. However, the predominant method by which the coating promotes fixation is currently unknown.

The purpose of the current study is to examine whether the osteoinductive properties of the coating can be attributed mainly to the topography or chemistry of the coating surface or whether the combination is crucial. Therefore, three hypotheses will be tested; (1) that the BoneMaster topography causes an osteoinductive response, (2) that the BoneMaster chemistry causes an osteoinductive response, and (3) that the combination of BoneMaster topography and chemistry causes an osteoinductive response in osteoblasts.

\section{MATERIALS AND METHODS}

\section{Sample Preparation}

Four different surfaces were analysed in this study; BoneMaster-coated titanium alloy (BM), Thermanox coverslips (Thx), gold sputter-coated BoneMaster (BM-Au) and Thermanox (Thx-Au) samples.

The BoneMaster coated samples were prepared by Biomet Deutschland $\mathrm{GmbH}$ in the same manner as that performed by Roessler et al. [9]. The substrates used were discs of titanium alloy (Ti6Al4V, ASTM 136) of $10 \mathrm{~mm}$ diameter and height $2 \mathrm{~mm}$; these were grit blasted prior to BoneMaster coating. The Thermanox coverslips (NUNC) were $13 \mathrm{~mm}$ diameter and $0.2 \mathrm{~mm}$ thick. Sputter coating of gold onto the BoneMaster and Thermanox samples was performed using a SC7640 Polaron sputter coater at a voltage of $2.2 \mathrm{kV}$ and a plasma current of $17 \mathrm{~mA}$ in an argon atmosphere at 0.04-0.02 mbar pressure. The coating was applied for 60 seconds with a working distance of $50 \mathrm{~mm}$. 


\section{Surface Characterisation}

The surfaces were characterised prior to analysis to determine the chemical and topographical nature and to confirm the uniformity of the gold coating. Elemental analysis was performed using X-ray Photoelectron Spectroscopy (XPS). A VG Scientific ESCALAB Mark 1 spectrometer was using with polychromatic AL K $\alpha$ X-rays at an anode potential of $10 \mathrm{kV}$ and a filament emission current of $20 \mathrm{~mA}$. The roughness of the BoneMaster coated samples was quantified using surface profilometry. A PhotoMap 3-D profilometer from Fogale NanoTech was used; four measurements were taken from each sample. Surface and cells were imaged using a Philips XL30 ESM-FEG scanning electron microscope (SEM) in wet mode using an accelerating voltage of $15 \mathrm{kV}$, a spot size of $3.0 \mu \mathrm{m}$ and between 2.3-2.4 Torr operating pressure.

\section{Cell Responses}

Human osteosarcoma TE-85 cells from the European Collection of Cell Cultures were cultured to passage 47 in Dulbecco's modified eagles medium (DMEM) supplemented with $10 \% \mathrm{v} / \mathrm{v}$ foetal calf serum (FCS), $2 \% \mathrm{v} / \mathrm{v}$ HEPES $(1 \mathrm{M}), 1 \% \mathrm{v} / \mathrm{v}$ glutamine $(200 \mathrm{mM}), 1 \% \mathrm{v} / \mathrm{v}$ non-essential amino acids $(10 \mathrm{mM}), 2 \% \mathrm{v} / \mathrm{v}$ antibiotic/antimycotic and $15 \% \mathrm{w} / \mathrm{v}$ ascorbic acid. All items were purchased from Invitrogen Ltd. Cells were cultured at $37^{\circ} \mathrm{C}$ and $5 \% \mathrm{CO}_{2}$. Media was replaced every two days. For the assays, cells were seeded onto the samples at a density of 40,000 cells per $\mathrm{cm}^{2}$.

Cell proliferation was measured using an Alamar blue assay, this was performed on the samples after 1, 4, 7 and 14 days of culture $(n=3)$. One millilitre of $10 \%$ v/v solution of Alamar Blue (ABD Serotec) concentrate in Hank's Buffered Salt Solution (HBSS) was added to the samples after washing 3 times in PBS. Samples were then incubated for 80 minutes and then shaken at $300 \mathrm{rpm}$ on a Heidolph Titramax 100 plate shaker for 10 minutes. The fluorescence was measured of $100 \mu \mathrm{m}$ aliquots of each well using a FLX 800 Microplate Reader; $530 \mathrm{~nm}$ excitation was used and emission measured at $590 \mathrm{~nm}$.

In order to examine cell differentiation, alkaline phosphatase and osteocalcin assays were performed and normalised by DNA content. Analysis was performed at predetermined time points. For alkaline phosphatase activity assessment, after 1, 4, 7 and 14 days of culture $(n=3)$, samples were removed from the Alamar Blue solution and washed 3 times in PBS, and then $1 \mathrm{ml}$ of sterile water was added. Samples were then frozen $\left(-20{ }^{\circ} \mathrm{C}\right)$ and thawed $\left(37^{\circ} \mathrm{C}\right)$ more than three times. Then $50 \mu \mathrm{l}$ of cell lysate and $50 \mu \mathrm{l}$ of alkaline phosphatase reagent (Randox Laboratories UK, Cat.No AP307) were added to a well plate. Plates were shaken for 4 minutes at $300 \mathrm{rpm}$ on a Heidolph Titramax 100 plate shaker in a dark environment. The absorbance was then measured using a Bio-Tek ELx 800 colorimetric microplate reader at a wavelength of $405 \mathrm{~nm}$ and a $630 \mathrm{~nm}$ reference filter. 
To quantify the DNA content of the cell layer, $100 \mu \mathrm{l}$ of cell suspension was mixed with $100 \mu \mathrm{l}$ of Hoechst 33258 stain $(2 \mathrm{mg} / \mathrm{ml}$ in TNE buffer). Calf Thymus DNA (Sigma, UK) was diluted in TNE buffer to various concentrations $(0.125 \mu \mathrm{g} / \mathrm{ml}-10 \mu \mathrm{g} / \mathrm{ml})$ to create a calibration curve. The fluorescence emitted at $460 \mathrm{~nm}$ after excitation at $360 \mathrm{~nm}$ was measured using FLx 800 fluorescence microplate reader, and using the calibration data, the DNA content per $\mathrm{ml}$ of cell suspension was determined.

An osteocalcin assay was carried out using an osteocalcin ELISA Kit (Invitrogen KAQ1381) according to manufacturer's instructions. Data was normalised by DNA content in the same manner as carried out on the alkaline phosphatase assay. Analysis was performed after 15 and 21 days of culture ( $\mathrm{n}=3)$.

For SEM examination, cells were fixed with glutaraldehyde (3\% v/v) in sodium cacodylate buffer $(0.1 \mathrm{M})$ for 30 minutes, then left in $7 \%$ sucrose solution in cacodylate buffer $(0.1 \mathrm{M})$ for 5 minutes at $4{ }^{\circ} \mathrm{C}$ and then washed. Cells were then post-fixed with $1 \% \mathrm{w} / \mathrm{v}$ osmium tetroxide solution for 45 minutes, then dehydrated with; 20, 40, 60, 70, 80 and $90 \% \mathrm{v} / \mathrm{v}$ ethanol for $5 \mathrm{~min}$, then twice in $100 \%$ ethanol for $5 \mathrm{~min}$, before drying via hexadimethyldisilazane (HMDS). Samples were gold coated, as before, prior to viewing using an FEI XL30 SEM.

\section{Statistical Analysis}

Statistical analysis was carried out using Prism 3.0 (Graphpad, USA). Significant differences in cell responses to experimental substrate groups were determined by one-way analysis of variance with a Bonferroni post test. An independent samples Student t-test was used to assess the effect of gold coating on substrate roughness. Differences were considered significant if $\mathrm{p}<0.05$.

\section{RESULTS}

\section{Surface Characterisation}

Prior to cell culture, the surfaces were characterised using XPS, SEM and optical profilometry in order to examine the elemental composition of the surfaces, the surface topography and nano- and micro-roughness. The XPS spectra (Figure 1) for the uncoated BoneMaster samples identified oxygen, calcium, carbon and phosphate on the surface of the samples. The gold-coated BoneMaster sample spectra only showed gold and carbon.

SEM images were taken of the gold-coated BoneMaster samples to examine the morphology of the surface after gold-coating (typical image shown in Figure 2). The surfaces showed a needle-like morphology, of average approximate length $300 \mathrm{~nm}$. 
Optical profilometry assessment of the uncoated BoneMaster and gold-coated BoneMaster samples indicated a very similar appearance (Figure 3 ) and the $\mathrm{R}_{\mathrm{a}}$ values which were calculated from them showed no significant difference between the two sample sets $(\mathrm{p}=0.341$, Table 1$)$.

\section{Cell Responses}

The HOS cells were imaged using SEM after culture on the different sample surfaces for 1, 4, 7 and 14 days. The cells after 1 day appeared well adhered, lamellopodia could be observed on all surfaces, extensive filopodia were apparent on Thermanox surfaces (Figure 4). By 7 days, a confluent cell layer was present on all samples (Figure 4).

Cell proliferation was assessed using the Alamar Blue assay; the results of which are shown in Figure 5. The cell number on all samples increased with time. After 14 days of culture the BoneMaster samples (BM and BM-Au) showed 27.6\% higher cell numbers compared with the Thermanox slides (Thx and Thx-Au); this was a significant difference $(\mathrm{p}=0.007)$. No difference was found between the BM and BM-Au samples when compared with each other $(\mathrm{p}=0.276)$; the same was true of the Thx and Thx-Au samples $(\mathrm{p}=0.106)$.

Alkaline Phosphatase activity (Figure 6), varied between Thermanox substrates and BM substrates over the course of the experiment. Alkaline phosphatase activity on the Thermanox samples peaked at day 4 and was consistently lower than the activity measured for the BoneMaster; at 7 and 14 days the alkaline phosphatase activity on the BoneMaster samples was significantly greater (day 7: $\mathrm{p}=0.0012$, day $14: \mathrm{p}=0.0034$, respectively) compared with the Thermanox samples. No difference in alkaline phosphatase activity was observed between the gold-coated and uncoated versions of either the BoneMaster (day 7: $\mathrm{p}=0.15$, day 14: $\mathrm{p}=0.56$ ) or Thermanox surface (day 7: $\mathrm{p}=0.13$, day 14: $\mathrm{p}=0.14)$.

The osteocalcin concentration, normalised by DNA, is shown in Figure 7. At both the 15 day and 21 day time points, the BM and BM-Au samples showed significantly greater osteocalcin concentration compared with the Thx and Thx-Au samples (day 15: $\mathrm{p}=0.0002$, day 21: $\mathrm{p}=0.001$ ). At 15 days the BM-Au sample showed greater osteocalcin concentration compared to the $\mathrm{BM}(\mathrm{p}=0.052)$; however, by 21 days there was no significant difference between the sample sets $(\mathrm{p}=0.29)$. The Thx and Thx-Au samples showed no significant different at either time point (day 15: $\mathrm{p}=0.41$, day 21: $\mathrm{p}=0.072$ ).

\section{DISCUSSION}

The in-vitro experimental approach taken in this study allowed for the assessment of the relative contribution of selected surface properties to osteoblast-like cell responses with some confidence. The XPS spectra of the BM sample showed evidence of calcium, phosphate and oxygen, confirming that hydroxyapatite was on the surface. After gold-coating of the samples, calcium, phosphate and oxygen could no longer be detected, with gold and 
carbon being the only detectable elements; confirming that the hydroxyapatite had become completely covered in a continuous gold layer, thus completely altering the chemistry of the surface. Carbon was seen in both spectra; however, it is thought that this was adventitious carbon contamination of the surface and was not related to the coating.

An SEM image of the gold-coated BoneMaster sample illustrated a needle-like morphology, similar to that reported by Roessler et al. [9] for electrochemically deposited hydroxyapatite coatings. This indicated that the morphology of the underlying hydroxyapatite coating was retained after gold-coating. The equivalent roughness observed between the BoneMaster samples and the gold-coated BoneMaster samples supported this finding, providing further evidence that the surface morphology was unaffected by the gold coating.

Significant differences in cell proliferation and in markers of osteoblastic phenotype were apparent between BoneMaster and the Thermanox samples after 14 days of culture; both with or without gold coating. This data would indicate that the gold coating of BM surfaces did not significantly alter cell responses to this substrate, which in turn indicates that the osteoblastic phenotype is promoted, not by the chemistry of the BM surface, but by its topography.

These observations are consistent with other studies examining the influence of biomaterial surface texture on osteoblastic phenotype. Such studies have demonstrated the effectiveness of moderate surface roughness (1-2 $\mu \mathrm{m})$ or micron scale topography in the promotion of osteoblastic attachment, proliferation, differentiation and matrix production [11, 12]. Further studies have recognised the contribution of such surface features in the promotion of bone formation in the surrounding tissue via promotion of specific cytokine and growth factor production by cells in contact with implant surfaces [13,14]. In addition to the degree of roughness, specific textures or organisation of topographic features have also been demonstrated to be important in the responses described above, both at the micro and nanoscale $[15,16]$. The BoneMaster coating is made up of crystallites of length approximately $300 \mathrm{~nm}$ and a diameter of $60 \mathrm{~nm}$ [9]. Use of laser interference lithography techniques has enabled the responses of osteoblasts to controlled surface morphologies to be assessed; it is known that osteoblasts can detect and respond to surface features as small as $50 \mathrm{~nm}$ [17] and that osteoblasts respond particularly strongly to features between $150 \mathrm{~nm}$ and $300 \mathrm{~nm}[17]$.

There are several biomedical coatings designed to promote osseointegration, which rely on the osteoblast response to the surface topography; these are predominantly used in the dental industry and include; NanoTite (Biomet 3i), TiOblast (Astra Tech), OsseoSpeed (Astra Tech), Lifecore RBM (Lifecore Biomedical), TiUnite (Nobel Biocare), and SLA (Straumann) [18]. There is evidence that these nano-structured titanium surfaces promote osseointegration [19], and the surface texture can upregulate the early expression of bone sialoprotein (BSP) and osteopontin (OPN) [20]. 
The above consideration should not be taken to exclude any influence of surface chemistry. The results from this study did not see any significant effect due to chemistry; nevertheless, across the range of assays used the results for the BM samples were higher compared with the BM-Au samples. However, the error was too large for these differences to be considered significant in the individual assays. Whilst cells were not in direct contact with the BoneMaster coating in the BM-Au group release of ions from the BoneMaster coating cannot be ruled out. It has been reported in numerous studies that elevated calcium ion levels at implant surfaces promotes osteoblastic phenotype [21]. Calcium ion levels in the culture medium were not measured.

The results shown in this study provide interesting insight into how osteoblast-like cells are affected by the topography of the surface on which they adhere. The needle-like morphology of the BoneMaster could be responsible for the increased osteoblastic activity observed compared with the Thermanox control; or it may have been features on a different scale. However, the similarity of the needle-like morphology of the BoneMaster surface and that of the HA crystals in natural bone may indicate a relation [9]. This may go some way to try and explain the increased bone density seen clinically by Bøe et al. [18] during the early stages of bone remodeling as compared to a conventional plasma sprayed HA coating.

\section{CONCLUSION}

This study appears to show that direct contact with HA is not necessary for the in vitro HOS cell response observed on BoneMaster samples. This does not rule out the influence of locally increased calcium and phosphate ion concentrations on the observed responses both in vitro and in vivo, but does suggest that topography or texture is a major contributing factor to the in vivo response to the BoneMaster coating.

\section{ACKNOWLEDGEMENTS}

The authors would like to thank Andreas Sewing at Biomet Deutschland GmbH for providing the BoneMaster coated discs which were examined in this study. In addition, we would like to thank Julie Thornhill for her help with the SEM imaging and Martin Roe for taking the XPS spectra. 


\section{REFERENCES}

1. Furlong, R., Osborn, J. Fixation of hip prostheses by hydroxyapatite ceramic coatings, J Bone Joint Surg [Br], 1991: 73: 741-5.

2. Goldring, S., Clark, C., Wright, T. The problem in total joint arthroplasty: aseptic loosening, J Bone Joint Surg [Am], 1993: 75: 799.

3. Collier, J.P., Surprenant, V.A., Mayor, M.B., Wrona, M., Jensen, R.E., Surprenant, H.P. Loss of hydroxyapatite coating on retrieved, total hip components, J Arthoplasty, 1993: 8: 389-93.

4. Morscher, E., Hefti, A., Aebi, U. Severe osteolysis after third-body wear due to hydroxyapatite particles from acetabular cup coating, J Bone Joint Surg [Br], 1998: 80: 267-72.

5. Tsui, Y., Doyle, C., Clyne, T. Plasma sprayed hydroxyapatite coatings on titanium substrates Part 1: Mechanical properties and residual stress levels, Biomaterials, 1998: 19: 2015-30.

6. Yang, Y.C., Chang, E. Influence of residual stress on bonding strength and fracture of plasmasprayed hydroxyapatite coatings on Ti-6Al-4V substrate, Biomaterials, 2001: 22: 1827-36.

7. ASTM C-633-01. Standard Test Method for Adhesion or Cohesion Strength of Thermal Spray Coatings. Pennsylvania: ASTM International 2008.

8. Zyman, Z., Weng, J., Liu, X., Zhang, X., Ma, Z. Amorphous phase and morphological structure of hydroxyapatite plasma coatings, Biomaterials, 1993: 14: 225-8.

9. Roessler, S., Sewing, A., Stölzel, M., Born, R., Scharnweber, D., Dard, M., et al. Electrochemically assisted deposition of thin calcium phosphate coatings at near physiological $\mathrm{pH}$ and temperature, J Biomed Mat Res A, 2003: 64: 655-63.

10. Schliephake, H., Scharnweber, D., Dard, M., Roessler, S., Sewing, A., Hüttmann, C. Biological performance of biomimetic calcium phosphate coating of titanium implants in the dog mandible, J Biomed Mat Res A, 2003: 64: 225-34.

11. Cooper, L.F., Masuda, T., Whitson, S.W., Yliheikkilä, P., Felton, D.A. Formation of mineralizing osteoblast cultures on machined, titanium oxide grit-blasted, and plasma-sprayed titanium surfaces, The International journal of oral \& maxillofacial implants, 1999: 14: 37.

12. Lincks, J., Boyan, B., Blanchard, C., Lohmann, C., Liu, Y., Cochran, D., et al. Response of MG63 osteoblast-like cells to titanium and titanium alloy is dependent on surface roughness and composition, Biomaterials, 1998: 19: 2219.

13. Kieswetter, K., Schwartz, Z., Hummert, T., Cochran, D., Simpson, J., Dean, D., et al. Surface roughness modulates the local production of growth factors and cytokines by osteoblast-like MG-63 cells, J Biomed Mat Res A, 1996: 32: 55-63.

14. Boyan, B.D., Sylvia, V.L., Liu, Y., Sagun, R., Cochran, D.L., H Lohmann, C., et al. Surface roughness mediates its effects on osteoblasts via protein kinase $A$ and phospholipase $A_{2}$, Biomaterials, 1999: 20: 2305-10.

15. Buser, D., Schenk, R., Steinemann, S., Fiorellini, J., Fox, C., Stich, H. Influence of surface characteristics on bone integration of titanium implants. A histomorphometric study in miniature pigs, J Biomed Mat Res A, 2004: 25: 889-902.

16. Dalby, M.J., McCloy, D., Robertson, M., Wilkinson, C.D.W., Oreffo, R.O.C. Osteoprogenitor response to defined topographies with nanoscale depths, Biomaterials, 2006: 27: 1306-15.

17. Lamers, E., Frank Walboomers, X., Domanski, M., te Riet, J., van Delft, F.C.M.J.M., Luttge, R., et al. The influence of nanoscale grooved substrates on osteoblast behavior and extracellular matrix deposition, Biomaterials, 2010: 31: 3307-16.

18. Svanborg, L.M., Andersson, M., Wennerberg, A. Surface characterization of commercial oral implants on the nanometer level, J Biomed Mat Res B, 2010: 92B: 462-9. 
19. Östman, P.-O., Wennerberg, A., Albrektsson, T. Immediate Occlusal Loading of NanoTite ${ }^{\mathrm{TM}}$ PREVAIL ${ }^{\circledR}$ Implants: A Prospective 1-Year Clinical and Radiographic Study, Clin Implant Dent Relat Res, 2010: 12: 39-47.

20. Tambasco de Oliveira, P., Nanci, A. Nanotexturing of titanium-based surfaces upregulates expression of bone sialoprotein and osteopontin by cultured osteogenic cells, Biomaterials, 2004: 25: 403-13.

21. Maeno, S., Niki, Y., Matsumoto, H., Morioka, H., Yatabe, T., Funayama, A., et al. The effect of calcium ion concentration on osteoblast viability, proliferation and differentiation in monolayer and 3D culture, Biomaterials, 2005: 26: 4847-55.

\section{Figures and Tables}

\begin{tabular}{l|l}
\hline Samples & Surface Roughness, $\mathbf{R}_{\mathbf{a}} / \boldsymbol{\mu m}$ \\
\hline $\mathrm{BM}$ & $2.2 \pm 0.13$ \\
$\mathrm{BM}-\mathrm{Au}$ & $2.5 \pm 0.30$ \\
\hline
\end{tabular}

Table 1. Mean micro-scale $\mathrm{R}_{\mathrm{a}}$ roughness values measured from optical profilometry scans of the BoneMaster and gold-coated BoneMaster surfaces. The error shown is the standard error in the mean. 


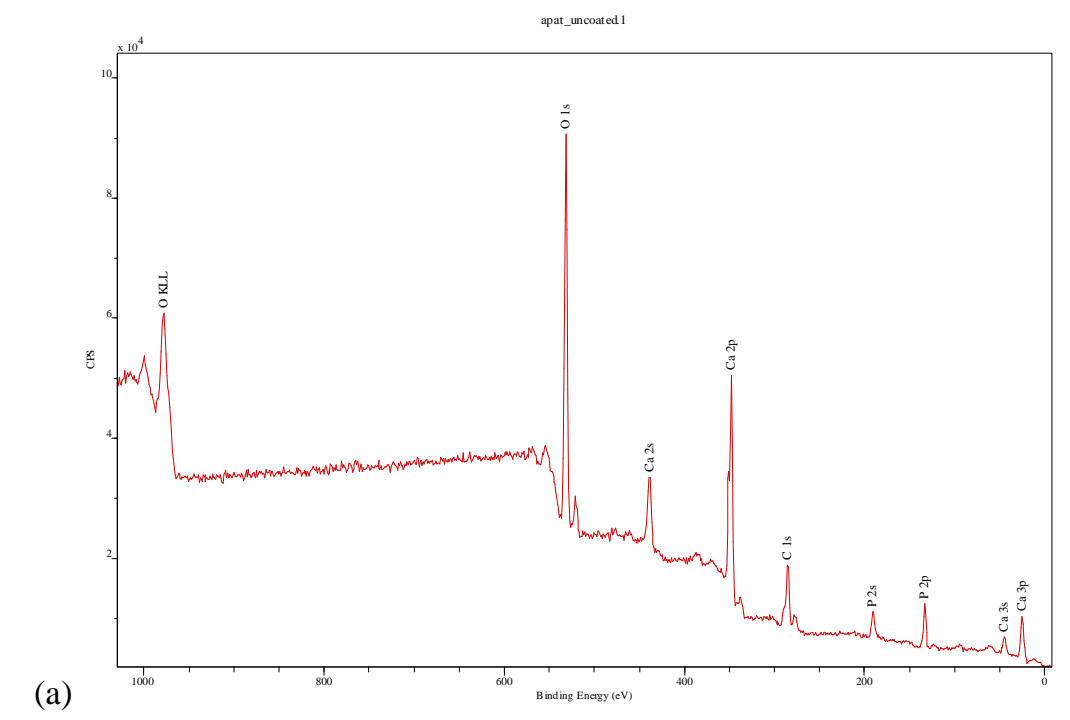

(a)

b)

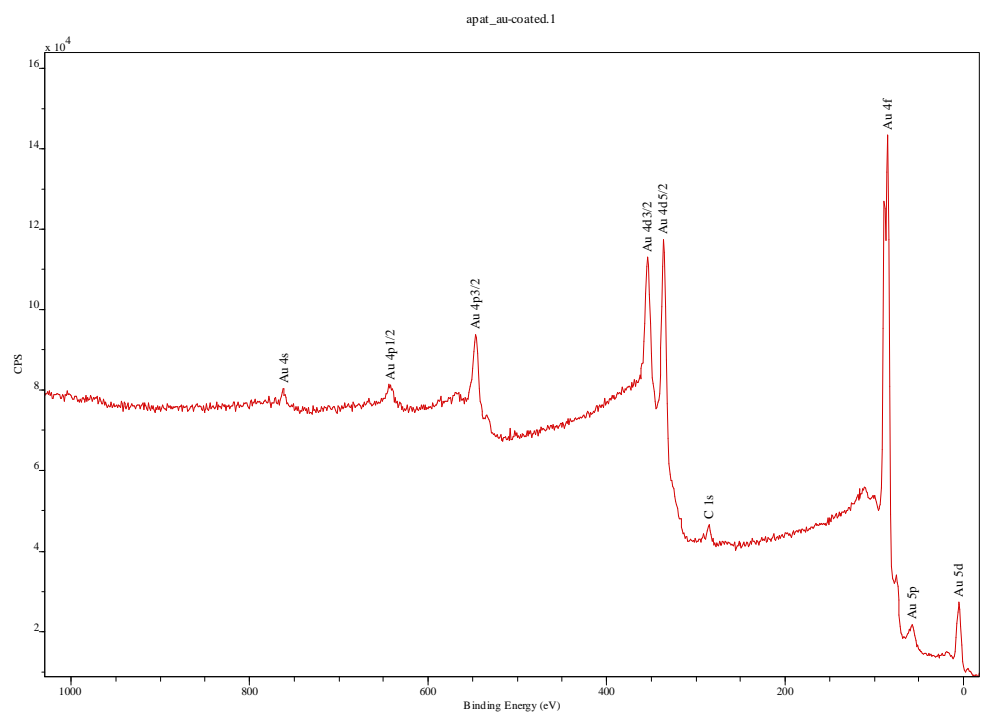

Figure 1. XPS spectra of the uncoated BoneMaster surface (a) and the gold-coated BoneMaster surface (b). Spectra taken with polychromatic $\mathrm{Al} \mathrm{K \alpha}$ X-rays with a $10 \mathrm{kV}$ potential and a current of $20 \mathrm{~mA}$; elemental peak identification is shown on the images. 


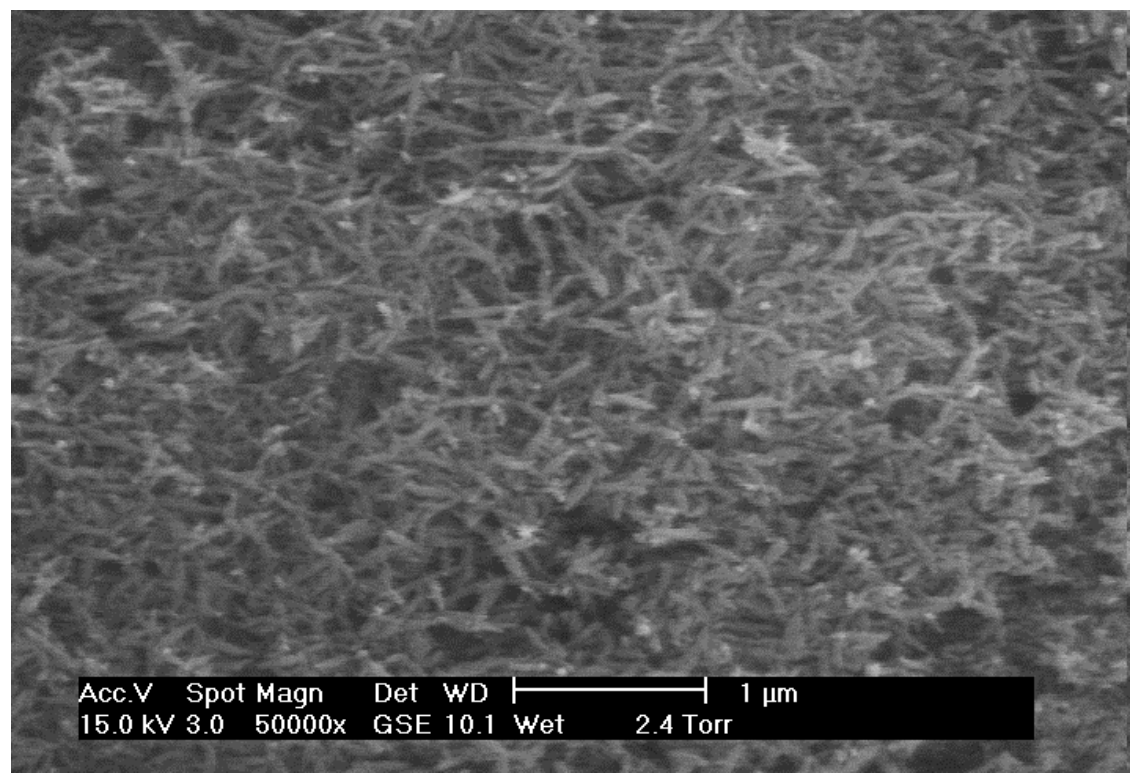

Figure 2. SEM micrograph of the gold-coated BoneMaster surface illustrating needle-like morphology. Image taken with an accelerating voltage of $15 \mathrm{kV}$ and a spot size of $3.0 \mu \mathrm{m}$. Scale bar shown on the image.

(a)
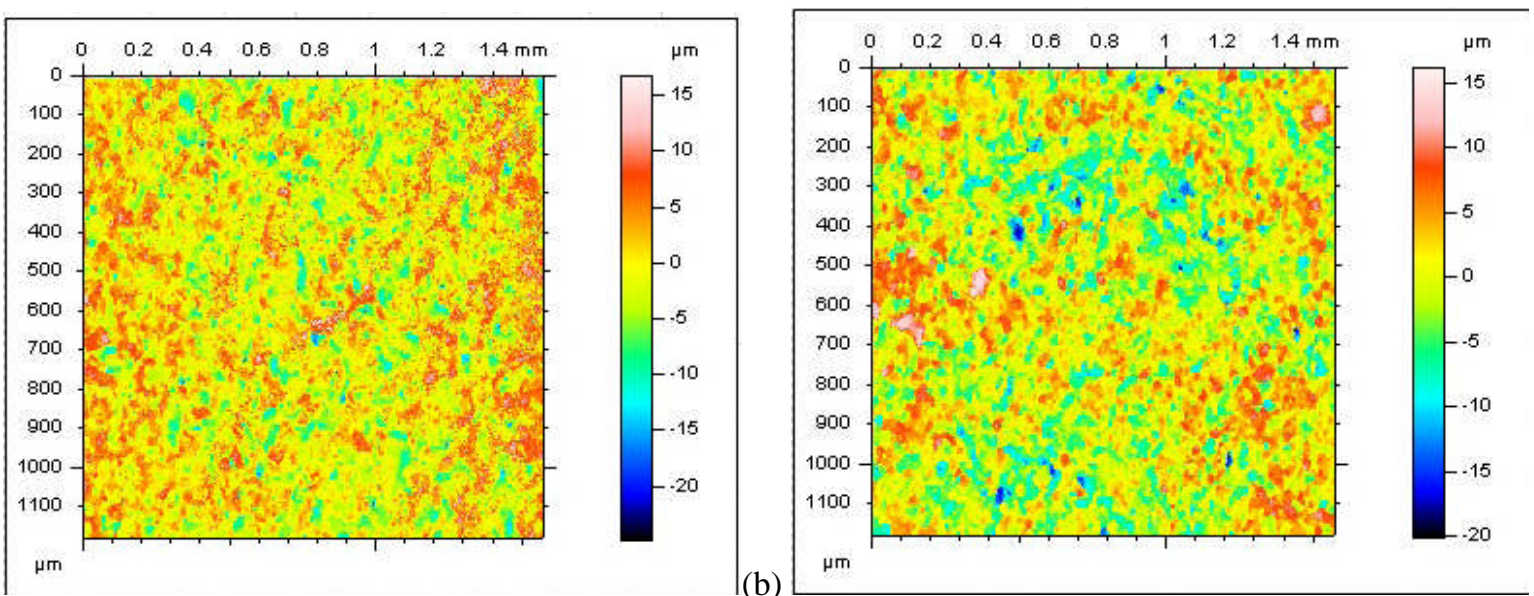

Figure 3. Optical prolifometry images of the uncoated BoneMaster samples (a) and the gold-coated BoneMaster samples (b). Scale bars are shown on the images. 

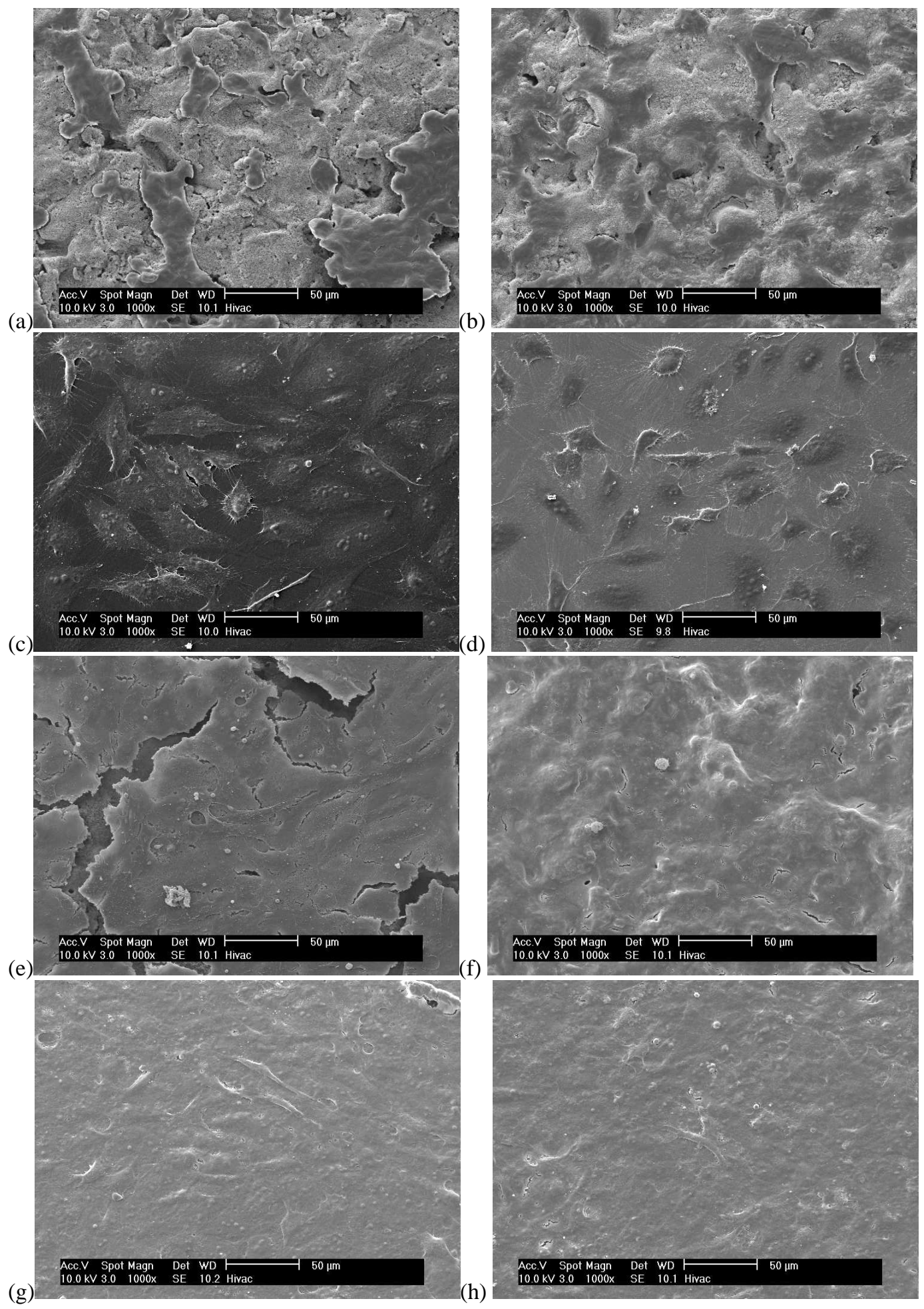

Figure 4. SEM micrographs of the HOS cells after culture on BoneMaster surfaces (a, e), gold-coated BoneMaster surfaces (b, f), Thermanox slides (c, g) and gold-coated Thermanox (d, h) slides for one and seven days respectively. Images taken with an accelerating voltage of $10 \mathrm{kV}$ and a spot size of $3.0 \mu \mathrm{m}$. Scale bars shown on the micrographs. 


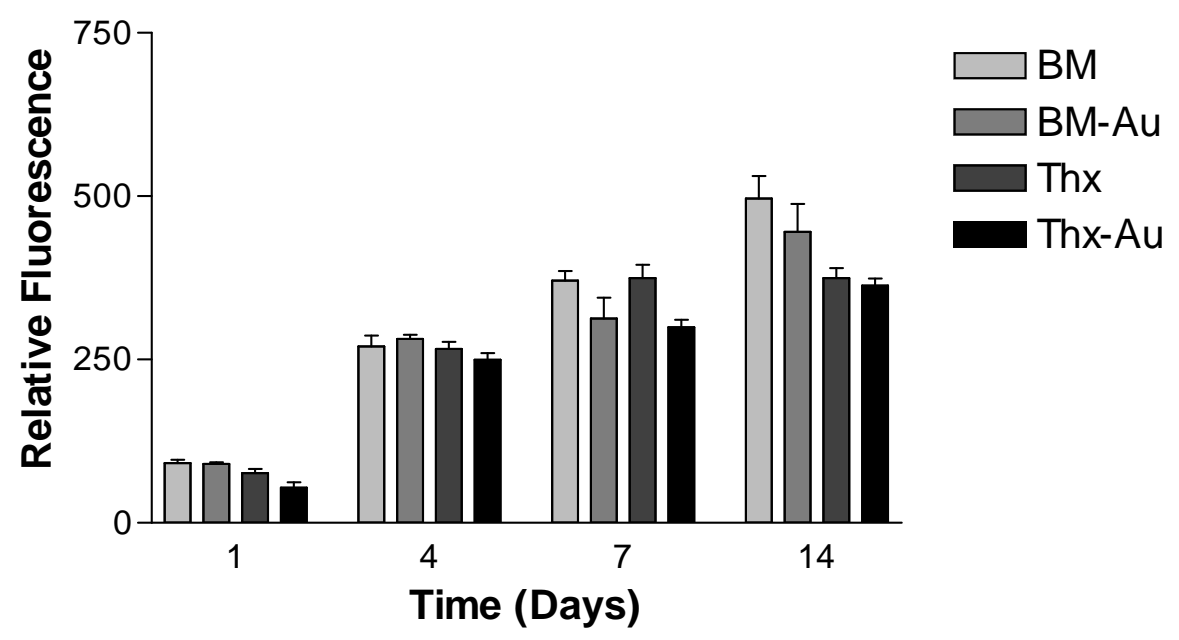

Figure 5. Cell proliferation of HOS cells cultured on BoneMaster, gold-coated BoneMaster, Thermanox and goldcoated Thermanox samples. Values are means and standard error in the mean.

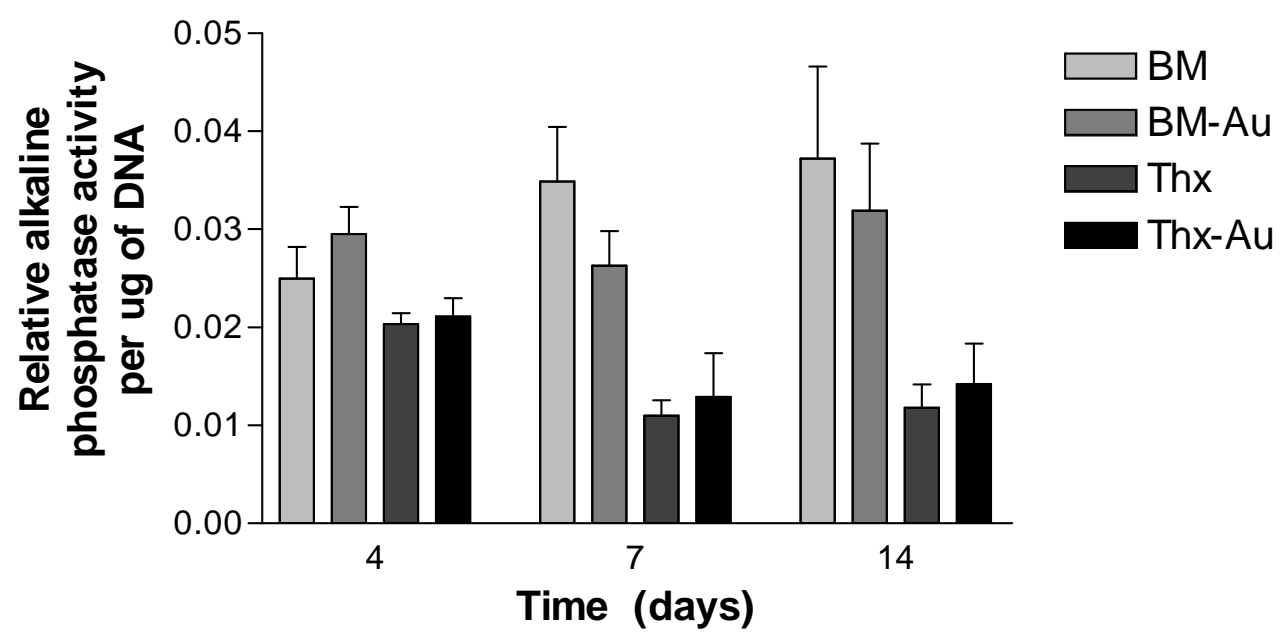

Figure 6. Relative alkaline phosphatase activity of HOS cells (normalised to DNA concentration) cultured for 1, 4, 7 and 14 days on BoneMaster, gold-coated BoneMaster, Thermanox and gold-coated Thermanox samples. Values are means and standard error in the mean. 


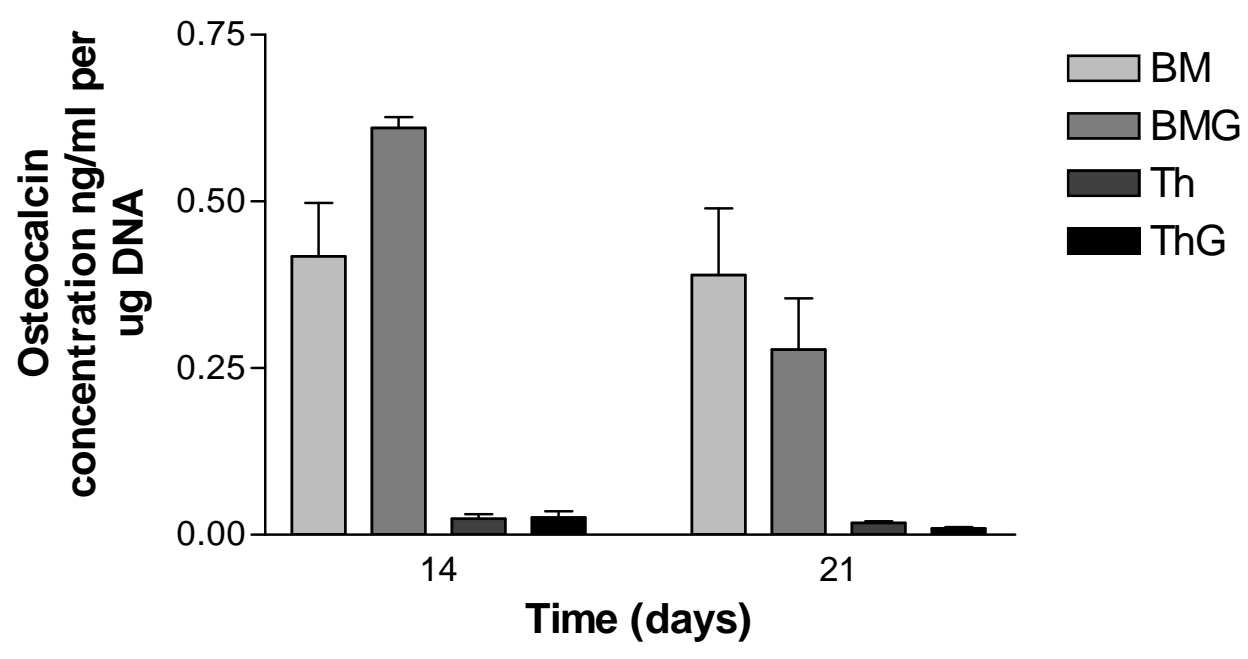

Figure 7. Osteocalcin concentration of HOS cells (normalised to DNA concentration) cultured for 1, 4, 7 and 14 days on BoneMaster, gold-coated BoneMaster, Thermanox and gold-coated Thermanox samples. Values are means and standard error in the mean. 